07,11

\title{
Прочностные свойства циркониевой керамики, упрочненной оксидом алюминия, с добавлением диоксида кремния
}

\author{
() А.А. Дмитриевский, Д.Г. Жигачева, А.О. Жигачев, П.Н. Овчинников \\ Тамбовский государственный университет им. Г.Р. Державина, \\ Тамбов, Россия, \\ E-mail: aadmitr@yandex.ru
}

Поступила в Редакцию 16 июня 2020 г.

В окончательной редакции 13 октября 2020 г.

Принята к публикации 14 октября 2020 г.

\begin{abstract}
Исследовано влияние примесей $\mathrm{Al}_{2} \mathrm{O}_{3}$ и $\mathrm{SiO}_{2}$ на прочностные свойства циркониевой керамики, стабилизированной оксидом кальция. Установлены оптимальные соотношения концентраций компонентов композиционной керамики $\mathrm{CaO}-\mathrm{ZrO}_{2}+\mathrm{Al}_{2} \mathrm{O}_{3}+\mathrm{SiO}_{2}$, при которых наблюдаются высокие значения предела прочности на изгиб $\sigma_{f}=980-70 \mathrm{MPa}$ (при $C_{\mathrm{Al}_{2} \mathrm{O}_{3}}=5 \mathrm{wt} . \%$ и $C_{\mathrm{SiO}_{2}}=0 \mathrm{~mol} . \%$ ) и предела прочности на сжатие $\sigma_{c}=2.44-0.15 \mathrm{GPa}$ (при $C_{\mathrm{Al}_{2} \mathrm{O}_{3}}=5 \mathrm{wt} . \%$ и $C_{\mathrm{SiO}_{2}}=5 \mathrm{~mol} . \%$ ). Обнаружено проявление признаков пластичности (появление площадки текучести на $\sigma-\varepsilon$-диаграммах сжатия) при введении $4-5 \%$ диоксида кремния в керамику $\mathrm{CaO}-\mathrm{ZrO}_{2}+\mathrm{Al}_{2} \mathrm{O}_{3}$.
\end{abstract}

Ключевые слова: циркониевая керамика, предел прочности на изгиб, предел прочности на сжатие, пластичность, структура, фазовый состав.

DOI: 10.21883/FTT.2021.02.50475.138

\section{1. Введение}

Керамики на основе диоксида циркония $\left(\mathrm{ZrO}_{2}\right)$ и оксида алюминия $\left(\mathrm{Al}_{2} \mathrm{O}_{3}\right)$ широко используются в металлургии, машиностроении, атомной, добывающей, перерабатывающей, электротехнической и легкой промышленности как материалы с превосходными механическими свойствами и высокой термической, химической и радиационной стойкостью [1]. Благодаря своей биоинертности, они востребованы в медицине (изготовление имплантатов различного назначения) $[2,3]$.

Комбинирование материалов позволяет совмещать лучшие качества компонентов, „маскируя“ их недостатки. В композитах $\mathrm{ZrO}_{2}+\mathrm{Al}_{2} \mathrm{O}_{3}$ сильные стороны циркониевой керамики (рекордная для оксидных керамик вязкость разрушения, высокие износостойкость, а также низкий коэффициент трения) сочетаются с достоинствами корундовой керамики (высокими значениями твердости, модуля Юнга и прочности на сжатие). В общем случае, в зависимости от соотношения концентраций $\mathrm{ZrO}_{2}$ и $\mathrm{Al}_{2} \mathrm{O}_{3}$ в композите, различают корундовую керамику, упрочненную диоксидом циркония (ZirconiaToughened Alumina или ZTA), и циркониевую керамику, упрочненную оксидом алюминия (Alumina-Toughened Zirconia или ATZ) [4-5]. В последнем случае достижению высоких показателей механических свойств композита способствует одновременное проявление трансформационного и дисперсионного механизмов упрочнения. В основе дисперсионного механизма упрочнения лежит диссипация энергии распространяющейся трещины в результате ее отклонения от начального направления при „столкновении“ с более твердыми включениями (частицами) инородного материала [6]. Трансформационный механизм упрочнения, присущий диоксиду циркония [7], обусловлен фазовым переходом тетрагональной фазы $t-\mathrm{ZrO}_{2}$ (метастабильной при комнатной температуре) в термодинамически устойчивую моноклинную фазу $m-\mathrm{ZrO}_{2}$. Такой переход сопровождается изменением удельного объема указанных фаз и возникновением сжимающих механических напряжений, тормозящих распространение трещин.

Для стабилизации тетрагональной фазы $t-\mathrm{ZrO}_{2}$ при комнатной температуре обычно используют $\mathrm{Y}_{2} \mathrm{O}_{3}$, реже $\mathrm{CeO}_{2}, \mathrm{MgO}, \mathrm{CaO}$ и некоторые другие оксиды. От выбора стабилизатора во многом зависят не только достигаемые значения механических и трибологических свойств циркониевой керамики и композитов на ее основе, но и их стойкость к низкотемпературной деградации (самопроизвольное $t \rightarrow m$ превращение и связанное с этим ухудшение механических свойств $\mathrm{ZrO}_{2}$-керамики под действием влаги при сравнительно невысоких температурах [8]).

Управление свойствами композиционной керамики $\mathrm{ZrO}_{2}+\mathrm{Al}_{2} \mathrm{O}_{3}$ (с учетом потенциального использования конечных изделий) возможно благодаря вариативности ее состава и структуры. Структура композитов $\mathrm{ZrO}_{2}+\mathrm{Al}_{2} \mathrm{O}_{3}$ (относительная плотность, размер зерен $\mathrm{ZrO}_{2}$ и $\mathrm{Al}_{2} \mathrm{O}_{3}$, характер их пространственного распределения и пр.) во многом определяется технологическими режимами изготовления керамики (помол, компактирование и спекание), а также наличием дополнительных примесей. Ранее нами было показано $[9,10]$, что комбинирование циркониевой керамики, стабилизированной оксидом кальция (6.5 mol.\%), с оксидом алюми- 
ния (5 wt.\%) и диоксидом кремния (5 mol.\%) позволяет достигать высоких соотношений твердости и вязкости разрушения композитов с сохранением высокой стабильности их фазового состава и механических свойств в условиях гидротермальных воздействий.

Для многих практических приложений ATZ- и ZTA-керамик большое значение имеют предел прочности на изгиб $\sigma_{f}$ и предел прочности на сжатие $\sigma_{c}$. Согласно многочисленным экспериментальным данным, образцы таких композитов, различающиеся составом и технологическими режимами изготовления, демонстрируют значительный разброс значений $\sigma_{f}$ и $\sigma_{c}$. В связи с этим, цель работы заключалась в исследовании влияния содержания $\mathrm{Al}_{2} \mathrm{O}_{3}$ и $\mathrm{SiO}_{2}$ на прочностные свойства ATZ-керамики (стабилизированной $\mathrm{CaO}$ ), режим синтеза которой обеспечивает высокое соотношение твердостьвязкость разрушения.

\section{2. Методика эксперимента}

Образцы ATZ-керамики изготавливали с использованием порошков $\mathrm{ZrO}_{2}$ (Sigma-Aldrich), $\mathrm{Al}_{2} \mathrm{O}_{3}$ (Hongwu), $\mathrm{CaO}$ (Reachem) и $\mathrm{SiO}_{2}$ (Sigma-Aldrich). Молярную концентрацию стабилизатора $(\mathrm{CaO})$ по отношению к $\mathrm{ZrO}_{2}$ сохраняли неизменной $\left(C_{\mathrm{CaO}}=6.5 \mathrm{~mol} \%\right)$. К полученной смеси добавляли $\mathrm{Al}_{2} \mathrm{O}_{3}$. Концентрацию оксида алюминия варьировали в интервале от 0 до $25 \mathrm{~mol} \%$. Молярную концентрацию диоксида кремния по отношению к смеси $\mathrm{CaO}-\mathrm{ZrO}_{2}+\mathrm{Al}_{2} \mathrm{O}_{3}$ (при концентрации $\left.C_{\mathrm{Al}_{2} \mathrm{O}_{3}}=5 \mathrm{wt} . \%\right)$ варьировали в диапазоне от 0 до $10 \mathrm{~mol} \%$.

Смеси порошков диспергировали ультразвуком в дистиллированной воде. Затем производили помол в планетарной мельнице Pulverisette (Fritsch) в течение $5 \mathrm{~h}$ шарами диаметром $1.5 \mathrm{~mm}$ при ускорении движения шаров $640 \mathrm{~m} / \mathrm{s}^{2}$. Полученную смесь сушили в печи при температуре $T_{0}=80^{\circ} \mathrm{C}$ в течение $24 \mathrm{~h}$. Образцы в виде ,таблеток“ формовали путем одноосного сухого прессования при нагрузке $500 \mathrm{MPa}$. Спекание образцов в электрической печи проводили в двухстадийном режиме $\left(T_{1}=1300^{\circ} \mathrm{C}\right.$ и $\left.T_{2}=1200^{\circ} \mathrm{C}\right)$, что согласно $[11,12]$ обеспечивает сохранение более мелкого среднего размера зерна и высокой плотности. Для диагностики прочности на сжатие $\sigma_{c}$ и прочности на изгиб $\sigma_{f}$ образцы вырезали в виде плоскопараллельных брусков с поперечным сечением $2 \times 2 \mathrm{~mm}$.

Определение предела прочности на изгиб (методом трехточечного изгиба) проводили с использованием универсальной испытательной машины Instron 3344 (INSTRON Limited) в режиме жесткой машины со скоростью смещения $1 \mu \mathrm{m} / \mathrm{s}$. Видеофиксацию образцов в процессе изгиба (со скоростью 10000 кадров в секунду) проводили с использованием скоростной видеокамеры Photron FASTKAM Mini UX100 M1. Определение предела прочности на сжатие проводили с использованием напольной двухколонной сервогидравлической испытательной машины MTS 870 Landmark (MTS) в режиме жесткой машины со скоростью смещения $1 \mu \mathrm{m} / \mathrm{s}$. Относительную плотность образцов определяли методом Архимеда при помощи взвешивания на лабораторных весах с пределом чувствительности $0.001 \mathrm{~g}$. Исследование фазового состава и среднего размера кристаллитов осуществляли методом рентгенодифракционного анализа. Измерения проводили на дифрактометре D2 Phaser (Bruker AXS). Взаимодополняющим методом определения среднего размера кристаллитов служил анализ СЭМ-изображений поверхности образцов, полученных с использованием сканирующего электронного микроскопа высокого разрешения Merlin (CarlZeiss).

\section{3. Экспериментальные результаты и их обсуждение}

Установлено, что изготавливаемая в описанных выше технологических режимах циркониевая керамика (без примесей $\mathrm{Al}_{2} \mathrm{O}_{3}$ и $\mathrm{SiO}_{2}$ ) характеризуется низким (в сравнении с известными аналогами) значением предела прочности на изгиб $\sigma_{f}=300 \pm 70 \mathrm{MPa}$. Однако, введение малых (единицы процентов) концентраций оксида алюминия вызывает существенное увеличение значений $\sigma_{f}$ (рис. $\left.1, a\right)$. При $C_{\mathrm{Al}_{2} \mathrm{O}_{3}}=5 \mathrm{wt} . \%$ предел прочности на изгиб возрастает более чем троекратно и достигает значений $\sigma_{f}=980 \pm 70 \mathrm{MPa}$. Дальнейшее увеличение содержания $\mathrm{Al}_{2} \mathrm{O}_{3}$ в ATZ-керамике (в интервале от $5 \mathrm{wt} . \%$ до $25 \mathrm{wt} . \%$ ) приводит к постепенному уменьшению значений $\sigma_{f}$. Таким образом, показано, что зависимость $\sigma_{f}\left(C_{\mathrm{Al}_{2} \mathrm{O}_{3}}\right)$ имеет максимум при $C_{\mathrm{Al}_{2} \mathrm{O}_{3}}=5 \mathrm{wt} . \%$. Важно отметить, что оптимальное соотношение твердостьвязкость разрушения ATZ-керамики наблюдалось [9] при той же концентрации оксида алюминия.

Отметим также, что во всех исследованных образцах процесс разрушения при трехточечном изгибе протекал путем образования одной магистральной трещины. Во всех случаях трещина делила образец пополам проходила от линии, расположенной посередине между двумя нижними опорами (область с максимальными растягивающими напряжениями) к линии касания образца с верхней опорой (область с максимальными сжимающими напряжениями). В качестве примера, на врезке к рис. 1,a представлены два последовательных кадра высокоскоростной видеосъемки процесса разрушения образца ATZ-керамики.

Влияние примеси диоксида кремния на прочностные свойства ATZ-керамики исследовали на образцах, содержащих оксид алюминия в концентрации $C_{\mathrm{Al}_{2} \mathrm{O}_{3}}=5 \mathrm{wt} . \%$. Установлено, что вместо ожидаемого упрочнения (согласно [10], добавление $5 \mathrm{~mol} \% \mathrm{SiO}_{2}$ в ATZ-керамику увеличивает ее вязкость разрушения более чем на 40\%), диоксид кремния вызывает уменьшение предела прочности на изгиб исследуемой керамики (рис. $1, b)$. При этом, на зависимости $\sigma_{f}\left(C_{\mathrm{SiO}_{2}}\right)$ можно выделить две стадии: 

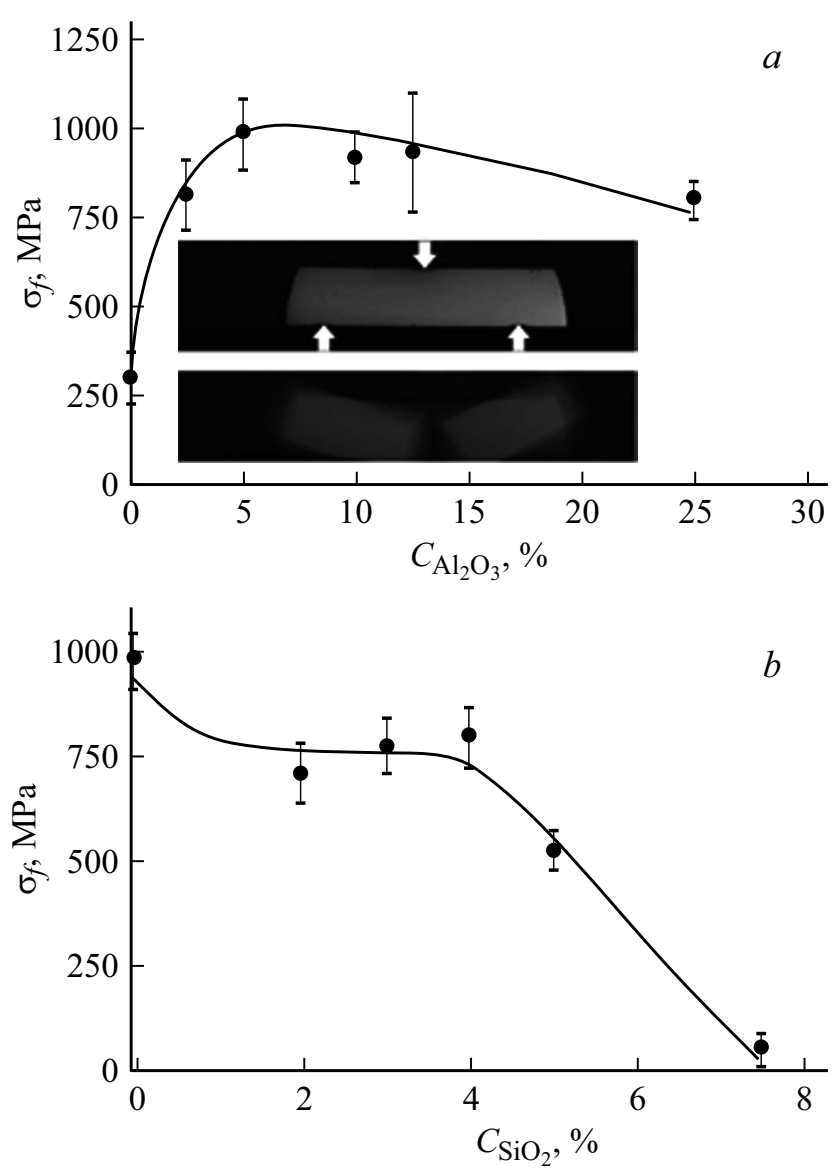

Рис. 1. Зависимости предела прочности при изгибе образцов $\mathrm{ATZ}$-керамики $(a)$ и кремнийсодержащей $\mathrm{ATZ}$-керамики $(b)$ от концентрации $\mathrm{Al}_{2} \mathrm{O}_{3}(a)$ и $\mathrm{SiO}_{2}(b)$. На врезке к рисунку $(a)$ представлены 2 последовательных кадра (с разницей во времени $\Delta t=10^{-4} \mathrm{~s}$ ) видеорегистрации процесса разрушения одного из образцов ATZ-керамики.

плавного $\left(C_{\mathrm{SiO}_{2}} \leq 4 \mathrm{~mol} . \%\right)$ и резкого $\left(C_{\mathrm{SiO}_{2}}>4 \mathrm{~mol} . \%\right)$ уменьшения предела прочности на изгиб.

При исследовании предела прочности на сжатие ATZ-керамики, напротив, выявлено положительное влияние примеси диоксида кремния. На рис. 2 представлены $\sigma-\varepsilon$-диаграммы для образцов ATZ-керамики $\left(C_{\mathrm{Al}_{2} \mathrm{O}_{3}}=5 \mathrm{wt} . \%\right)$ с нулевым, четырех и пятипроцентным содержанием диоксида кремния. Видно, что ATZ-керамике, не содержащей $\mathrm{SiO}_{2}$, соответствует $\sigma-\varepsilon$-диаграмма, характерная для хрупких материалов (рис. 2, кривая 1). Предел прочности на сжатие достигает значений $\sigma_{c}=2.11 \pm 0.15 \mathrm{GPa}$ при относительной деформации $\varepsilon=3.45 \pm 0.25 \%$. Введение диоксида кремния в ATZ-керамику приводит к качественному изменению характера $\sigma-\varepsilon$-диаграмм. На диаграмме появляется типичный для пластичных материалов участок (площадка текучести). Это свидетельствует о проявлении признаков пластичности у кремнийсодержащих образцов ATZ-керамики. Относительная деформация достигает значений $\varepsilon=5.7 \pm 0.3 \%$ (при $C_{\mathrm{SiO}_{2}}=4 \mathrm{~mol} . \%$ ) и $\varepsilon=5.25 \pm 0.25 \%$ (при $C_{\mathrm{SiO}_{2}}=5 \mathrm{~mol} . \%$ ). Предел прочности на сжатие при этом также увеличивается и достигает значений $\sigma_{c}=2.22 \pm 0.2 \mathrm{GPa}$ (при $C_{\mathrm{SiO}_{2}}=4 \mathrm{~mol} . \%$ ) и $\sigma_{c}=2.44 \pm 0.15 \mathrm{GPa}$ (при $C_{\mathrm{SiO}_{2}}=5 \mathrm{~mol} . \%$ ). Дальнейшее увеличение концентрации $\mathrm{SiO}_{2}$ в ATZ-керамике приводит к ее резкому охрупчиванию (падению предела прочности на сжатие).

Переходя к обсуждению полученных результатов, отметим, что наблюдаемые немонотонные зависимости прочностных свойств исследуемых керамик от содержания примесей $\left(\mathrm{Al}_{2} \mathrm{O}_{3}\right.$ и $\left.\mathrm{SiO}_{2}\right)$ являются результатом сложной комбинации проявлений трансформационного и дисперсионного механизмов упрочнения, а также

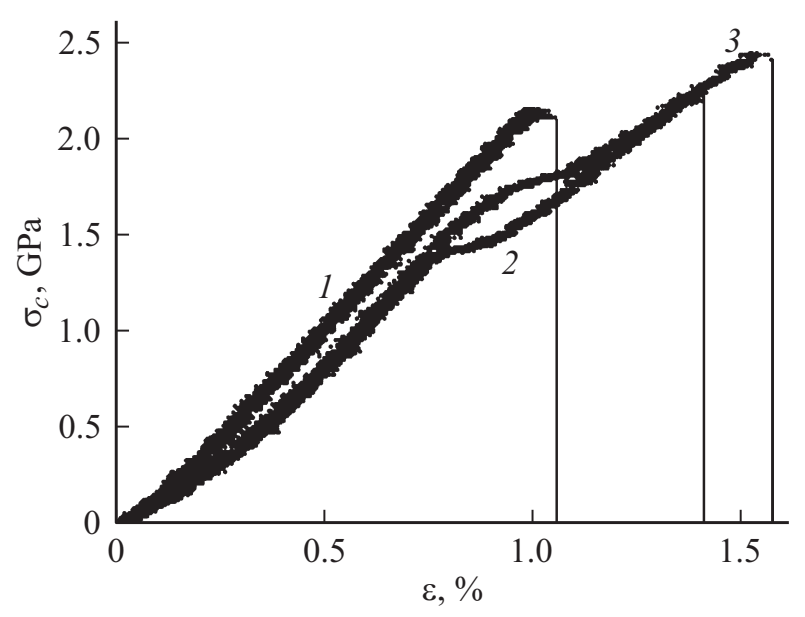

Рис. 2. Диаграммы напряжение-относительная деформация, зарегистрированные при одноосном сжатии образцов ATZ-керамики с концентрацией диоксида кремния 1) $C_{\mathrm{SiO}_{2}}=0 \mathrm{~mol} . \%$; 2) $C_{\mathrm{SiO}_{2}}=4 \mathrm{~mol} . \%$; 3) $C_{\mathrm{SiO}_{2}}=5 \mathrm{~mol} . \%$.

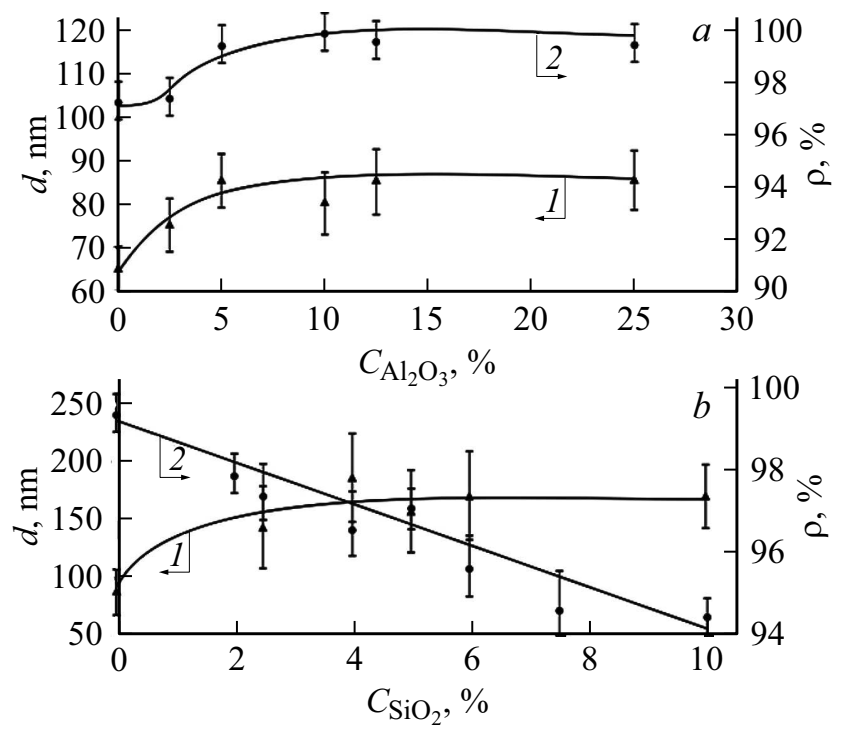

Рис. 3. Зависимости среднего размера кристаллитов (кривые 1) и относительной плотности (кривые 2) ATZ-керамики $(a)$ и кремнийсодержащей ATZ-керамики $(b)$ от концентрации $\mathrm{Al}_{2} \mathrm{O}_{3}(a)$ и $\mathrm{SiO}_{2}(b)$. 

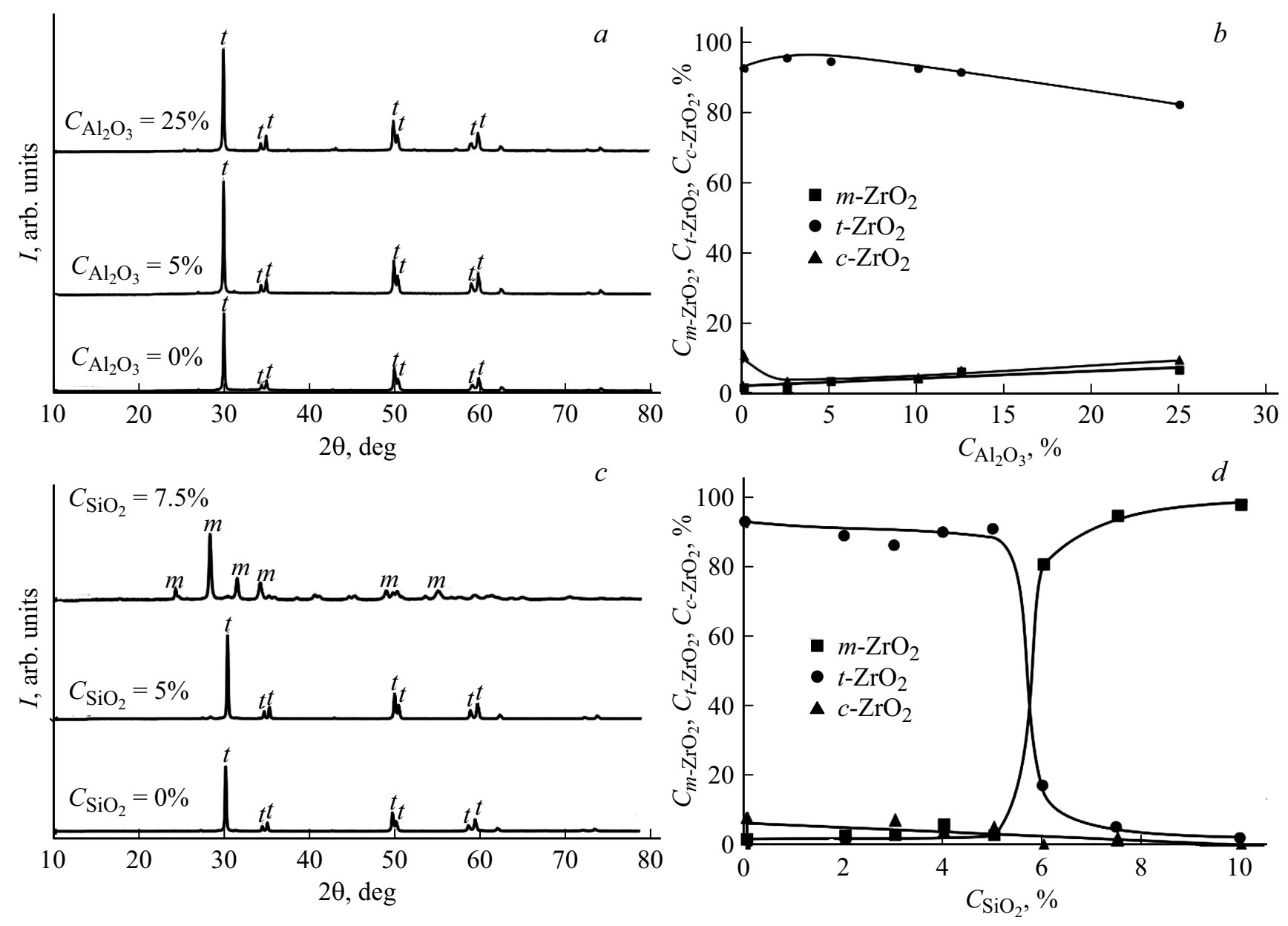

Рис. 4. Характерные дифрактограммы образцов циркониевой керамики с примесью $\mathrm{Al}_{2} \mathrm{O}_{3}(a)$ и $\mathrm{SiO}_{2}$ (c) и зависимости относительных долей моноклинной, тетрагональной и кубической фаз диоксида циркония от концентрации $\mathrm{Al}_{2} \mathrm{O}_{3}(b)$ и $\mathrm{SiO}_{2}(d)$.

модификации структуры и фазового состава керамик. Отметим, что эффективность дисперсионного механизма упрочнения нарастает с увеличением $C_{\mathrm{Al}_{2} \mathrm{O}_{3}}$, но достигает насыщения задолго до достижения условия $C_{\mathrm{Al}_{2} \mathrm{O}_{3}}=C_{\mathrm{ZrO}_{2}}$. Вместе с тем, увеличение концентрации $\mathrm{Al}_{2} \mathrm{O}_{3}$ эквивалентно уменьшению содержания $\mathrm{ZrO}_{2}$ в композите и, соответственно, снижению вклада трансформационного механизма упрочнения. Таким образом, „результирующая“ вкладов трансформационного и дисперсионного механизмов упрочнения ATZ-керамики нелинейно изменяется (имеет максимум) по мере увеличения концентрации оксида алюминия.

В отдельной серии измерений показано, что повышение концентрации оксида алюминия от 0 до $5 \mathrm{wt} . \%$ в безкремниевой ATZ-керамике сопровождается увеличением среднего размера кристаллитов $d$ и относительной плотности $\rho$ от $65 \mathrm{~nm}$ до $85 \mathrm{~nm} \mathrm{и} \mathrm{от} 97 \%$ до $99 \%$ соответственно (рис. 3,a). В интервале концентраций оксида алюминия $5 \mathrm{wt} . \%<C_{\mathrm{Al}_{2} \mathrm{O}_{3}}<25 \mathrm{wt} . \%$ значения $d$ и $\rho$ остаются неизменными (с учетом погрешности измерений). Дополнительное введение диоксида кремния в ATZ-керамику $\left(C_{\mathrm{Al}_{2} \mathrm{O}_{3}}=5 \mathrm{wt} . \%\right)$ сопровождается снижением ее относительной плотности от $99 \%$ до 94\% на фоне увеличения среднего размера кристаллитов от $85 \mathrm{~nm}$ до $170 \mathrm{~nm}$ (рис. $3, b)$.

Фазовый состав диоксида циркония также проявляет чувствительность к наличию примесей в керамике (в меньшей степени к $\mathrm{Al}_{2} \mathrm{O}_{3}$ и в большей степени к $\left.\mathrm{SiO}_{2}\right)$. В качестве примера, на рис. 4, $a$ и $c$ приведены дифрактограммы образцов ATZ-керамики с характерными концентрациями $\mathrm{Al}_{2} \mathrm{O}_{3}$ и $\mathrm{SiO}_{2}$. Количественный анализ данных рентгеновской дифрактометрии позволил получить зависимости относительных долей моноклинной $m-\mathrm{ZrO}_{2}$, тетрагональной $t-\mathrm{ZrO}_{2}$ и кубической $c-\mathrm{ZrO}_{2}$ фаз диоксида циркония от концентрации $\mathrm{Al}_{2} \mathrm{O}_{3}$ и $\mathrm{SiO}_{2}$ в ATZ-керамике (рис. $4, b$ и $d$ соответственно). Особое внимание привлекает резкое падение доли тетрагональной фазы $t-\mathrm{ZrO}_{2}$ и эквивалентное увеличение доли моноклинной фазы $m-\mathrm{ZrO}_{2}$ при превышении 5-процентного содержания $\mathrm{SiO}_{2}$.

Отметим, что добавление диоксида кремния в циркониевую керамику, содержащую в качестве стабилизатора $\mathrm{CaO}$, может сопровождаться образованием силикатов кальция. Это должно сопровождаться нарушением ба- 
ланса в соотношении концентраций $\mathrm{ZrO}_{2}$ и $\mathrm{CaO}$ (стабилизатора тетрагональной фазы $t-\mathrm{ZrO}_{2}$ ), что в свою очередь может вызвать повышение трансформируемости тетрагональной фазы диоксида циркония. Кроме того, в ATZ-керамике, содержащей $\mathrm{SiO}_{2}$ возможно образование алюмосиликатов. Однако это не может служить объяснением наблюдаемого изменения фазового состава диоксида циркония (рис. 4,c), поскольку $\mathrm{Al}_{2} \mathrm{O}_{3}$ в исследуемой керамике играет роль упрочняющей добавки (обеспечивает проявление дисперсионного механизма упрочнения), а не стабилизатора. В недавней работе [13] было показано, что введение $\mathrm{SiO}_{2}$ в ATZ-керамику, стабилизированную $\mathrm{CaO}$, приводит к снижению энергетического порога для $t \rightarrow m$ превращений (то есть к повышению трансформируемости) в области распространяющейся трещины.

Таким образом, отсутствие прямой пропорциональности изменения структуры и фазового состава ATZ-керамики а также вкладов трансформационного и дисперсионного механизмов упрочнения от концентраций $\mathrm{Al}_{2} \mathrm{O}_{3}$ и $\mathrm{SiO}_{2}$ обуславливает немонотонный и двухстадийный характеры зависимостей $\sigma_{f}\left(C_{\mathrm{Al}_{2} \mathrm{O}_{3}}\right)$ и $\sigma_{f}\left(C_{\mathrm{SiO}_{2}}\right)$ соответственно.

Появление пластической деформации ранее наблюдали в аморфных оксидах $\mathrm{ZrO}_{2}+\mathrm{Al}_{2} \mathrm{O}_{3}$ (при температурах $\left.500-700^{\circ} \mathrm{C}\right)[14,15]$, а также в пористых керамиках $\mathrm{ZrO}_{2}$ [16] и $\mathrm{Al}_{2} \mathrm{O}_{3}$ [17] при комнатных температурах. Увеличение пластичности связывали с деформационноиндуцированным образованием нанокристаллитов $t-\mathrm{ZrO}_{2}[14,15]$ и с возможностью перемещения локальных объемов материала в поровое пространство [16,17]. Выявление причин появления площадки текучести на $\sigma-\varepsilon$-диаграммах кремнийсодержащих ATZ-керамик с низким содержанием пор при комнатной температуре будет являться предметом ближайших исследований.

\section{4. Заключение}

В работе показано, что введение в циркониевую керамику мелкодисперсных частиц оксида алюминия $\left(C_{\mathrm{Al}_{2} \mathrm{O}_{3}}=5 \mathrm{wt} . \%\right)$ способствует повышению предела прочности на изгиб до значений $\sigma_{f}=980 \pm 70 \mathrm{MPa}$. Введение дополнительной примеси $\mathrm{SiO}_{2}$ (менее 5 mol.\%) вызывает снижение предела прочности на изгиб, но приводит к проявлению признаков пластичности (появлению площадки текучести на $\sigma-\varepsilon$-диаграммах сжатия), увеличению относительной деформации и предела прочности на сжатие до значений $\sigma_{c}=2.22 \pm 0.2 \mathrm{GPa}$ (при $\left.\quad C_{\mathrm{SiO}_{2}}=4 \mathrm{~mol} . \%\right) \quad$ и $\quad \sigma_{c}=2.44 \pm 0.15 \mathrm{GPa} \quad$ (при $C_{\mathrm{SiO}_{2}}=5$ mol.\%). Таким образом, введение оксида алюминия и диоксида кремния в ATZ-керамику (стабилизированную оксидом кальция) может быть использовано для улучшения комплекса механических свойств. При этом необходимо соблюдать строгое соотношение концентраций компонентов, поскольку превышение порогового значения концентрации $\mathrm{SiO}_{2}$ вызывает резкое ухудшение прочностных свойств ATZ-керамики.

\section{Благодарности}

Результаты были получены с использованием оснащения Центра коллективного пользования научным оборудованием ТГУ им. Г.Р. Державина. Авторы благодарят В. Васюкова и А. Денисова за помощь в проведении испытаний образцов на изгиб.

\section{Финансирование работы}

Исследование выполнено при финансовой поддержке РФФИ в рамках научного проекта № 19-03-00634.

\section{Конфликт интересов}

Авторы заявляют, что у них нет конфликта интересов.

\section{Список литературы}

[1] B. Basu, K. Balani. Advanced structural ceramics. Hoboken: Wiley (2011). $474 \mathrm{p}$.

[2] R. Galante, C.G. Figueiredo-Pina, A.P. Serro. Dent. Mater. 35, 6, 825 (2019).

[3] G. Soon, B. Pingguan-Murphy, K.W. Lai, S.A. Akbar. Ceram. Int. 4, 2543 (2016).

[4] M.H. Ghaemi, S. Reichert, A. Krupa, A. Zykova, K. Lobach, S. Sayenko, Y. Svitlychnyi. Ceram. Int. 43, 9746 (2017).

[5] S. Sequeira, M.H. Fernandes, N. Neves, M.M. Almeida. Ceram. Int. 43, 693 (2017).

[6] F. Zhang, L.F. Lin, E.Z. Wang. Ceram. Int. 41, 12417 (2015).

[7] R.H.J. Hannink, P.M. Kelly, B.C. Muddle. J. Am. Ceram. Soc. 83, 461 (2000).

[8] Y. Gaillard, E. Jimenez-Pique, F. Soldera, F. Mücklich, M. Anglada. Acta Mater. 56, 16, 4206 (2008).

[9] А.А. Дмитриевский, А.О. Жигачев, Д.Г. Жигачева, А.И. Тюрин. ЖТФ 89, 1, 107 (2019).

[10] А.А. Дмитриевский, Д.Г. Жигачева, Н.Ю. Ефремова, А.В. Умрихин. Рос. нанотехнологии 14, 3-4, 39 (2019).

[11] J. Binner, K. Annapoorani, A. Paul, I. Santacruz. J. Eur. Ceram. Soc. 28, 973 (2008).

[12] D. Galusek, K. Ghillányová, J. Sedláček, J. Kozankova. J. Eur. Ceram. Soc. 32, 1965 (2012).

[13] А.А. Дмитриевский, А.О. Жигачев, Д.Г. Жигачева, В.В. Родаев. ЖТФ 90, 12, 2108 (2020).

[14] A.S. Gandhi, V. Jayaram. Acta Mater. 51, 1641 (2003).

[15] X. Xiqing, Z. Chenxi, R. Haitao, G. Linlin, H. Feng, L. Jiachen. Ceram. Int. 43, 3453 (2017).

[16] С.П. Буякова., В. Хан, Д. Ли, Х. Чжэнь, Т.Ю. Саблина, А.Г. Мельников, С.Н. Кульков. Письма в ЖТФ 25, 17, 44 (1999).

[17] М.В. Григорьев, Н.Л. Савченко, С.П. Буякова, С.Н. Кульков. Письма в ЖТФ 43, 15, 79 (2017).

Редактор К.В. Емцев 